\title{
Reform and Innovation of Toy Design Teaching in Higher Vocational Colleges Under the Information Age
}

\author{
Sisu Chen ${ }^{1, *}$ \\ ${ }^{1}$ Guangdong Industry Polytechnic, Guangzhou, Guangdong, China \\ *Corresponding author. Email: 314192579@qq.com
}

\begin{abstract}
With the development of information technology, educational informationization has become the inevitable trend of higher vocational education reform. Based on the analysis of the teaching status of building block design course, this paper takes the application of graphics technology as the teaching entry point of building block toy course. With the form of digital simulation being adopted throughout the whole teaching course, this paper displays the development process of building blocks with graphical data simulation, establishes a direct and realtime evaluation of the course teaching form, and puts forward the measures of teaching reform of toy design course against the background of educational information.
\end{abstract}

Keywords: Graphic processing, Building block design, Toy design, Information age, Higher vocational education.

\section{INTRODUCTION}

With the real arrival of the era of "cloud computing, big data, Internet of things, mobile Internet", all walks of life are using the platform and information technology of the Internet, which combines the traditional industry with the Internet closely, and creates new business ecology in different fields. Since the lanch of the "Action Plan for Education Informationization 2.0" by the Ministry of Education, higher vocational education has accelerated the pace of information-based teaching, actively promoted "Internet + Education" with the core concept of the deep integration of information technology and education and teaching, so as to achieve a more open, suitable, peopleoriented, equal and sustainable education.

Building toys has become the third largest toy category after baby's toys and animation toys. With the increase of market size and brand, product innovation has become the inevitable trend of enterprise development, and the demand for talents and the model of product development are the difficulties faced by enterprises in their current development. As an output unit of talent cultivation at the back end of the industry, building block design course is an inevitable trend of the development of toy specialty. This type of curriculum is still in its infancy in China, with concept teaching as the core and lack of effective design evaluation mechanism, which leads to the lack of development standards for actual products in teaching. Information-based teaching has been developed in higher vocational colleges for more than 20 years, and graphic processing technology has been widely used in advertising, products, architecture and other professional teaching. Faster and more intuitive teaching information transmission is the advantage of graphics processing technology, and the update of graphics software also brings more humanized and more intelligent learning mode for the course teaching. The course combines MOOC, DingTalk, ICVE, WeChat Video, Tencent Meeting and other relevant online platforms to establish high-quality teaching resources and teaching mode. The hybrid teaching method combining online and offline approaches can meet students' personalized learning needs. At the same time, the rapid development of mobile phones also brings a mobile teaching platform for information-based teaching. 


\section{STATUS AND PROBLEMS}

As the largest toy manufacturing base in China, Guangdong Province has unique industrial resources, and the establishment of toy design specialty meets the needs of industrial regions. Because the toy design is a late starter in China, with lack of a systematic teaching system, the basically copied talent training model from product design, resulting in the talent training being not able to meet the needs of the actual skills of enterprises.

\subsection{The Limitation of Traditional Teaching of Building Block Design Course}

At present, the teaching of building blocks and toys in China is still in the form of teaching mainly based on theory. Traditional building blocks enterprises use building pellet products to carry out practical design and research and development, and have a high demand for site and building accessories, so it is difficult for school training sites to meet the standards of school-enterprise development. Single theory and information teaching cannot allow students to intuitively discover the practical problems in the development of building blocks and toys, nor can it facilitate connection between the teaching implementation with enterprise standards. Most vocational colleges can only take theoretical innovation as the knowledge training goal of the course, resulting in that students cannot reasonably apply this skill in the field of work after graduation, and the separation of teaching implementation and market standards has become a major problem in teaching. With the continuous growth of the market share of building blocks, enterprises have expanded the demand for innovative design talents, and the ability cultivation of building blocks and toy design teaching has become the thinking focus of professional development.

\subsection{A Good Integration Mechanism Has Not Yet Been Formed for Industry Resources}

As the world's largest toy producer, China's building blocks brand is also among the best in the world, with the most advanced production technology and management. The enterprise invests a lot of money every year to construct the product research and development mode with its own characteristics. It is fair to say that China has the most complete development and production chain of building blocks and toys. As the front-end work of the industry, toy design started late in China and teaching is still based on industrial design. There are more than 20 higher vocational colleges with toy specialty in China, which is under the teaching direction of product design specialty. Compared with other design professional, toy design lacks a complete teaching system and resources, it is difficult for students to obtain professional information, and teaching and learning transmission appears to be very limited. The general teaching content leads to the low matching rate of professional employment, and the graduates cannot meet the employment demand of enterprises. Rich industry resources cannot establish a good sharing mechanism with professional teaching, resulting in low teaching efficiency, knowledge points difficult to master and other problems.

\subsection{Information-based Teaching Lacks Pertinence}

Restricted by their own information knowledge and technical ability, many teachers often imitate the application of the information-based teaching mode of related majors indiscriminately in their own classrooms. Multimedia courseware, online resource database and course materials are not integrated and applied systematically, and the scattered teaching resources makes it difficult to give full play to the advantages of informationbased teaching. At the same time, the accuracy and rationality of teaching cannot be ensured only by converting classroom teaching content into information teaching structure based on the teachers' own understanding. In the teaching of graphic processing technology, each piece of software used should be unique to its profession, the teaching methods, training forms and tasks should all be corresponding to the teaching content of the major, and the scattered information resources and fuzzy teaching mode are the biggest problems in the course of building block design at present.

\section{TEACHING REFORM AND INNOVATION MEASURES OF TOY DESIGN SPECIALTY AGAINST THE BACKGROUND OF INFORMATION TECHNOLOGY}

With the development of the times and the progress of science and technology, the development and application of information 
technology has made earth-shaking changes in all walks of life. The construction of information technology improves work efficiency and industry competitiveness. In the education industry, information technology has long been the norm. Different from traditional teaching, information technology integrates education and industryrelated resources and enriches teaching methods and modes. Toy blocks design curriculum has integrated the classroom teaching by introducing the graphics technology, built development process through graphic data simulation, established an intuitive real-time assessment of teaching mechanism, set up digital visual monitoring, online teaching resource, information university-enterprise cooperation projects docking, etc. making the information-based teaching of building block design courses more in line with the demand of employment skills in today's enterprises.

\subsection{Information-based Teaching Enhances the Professionalism of Course Teaching}

The graphic processing technology is applied as the breakthrough point of the information-based teaching reform of building block toy design course, with digital simulation being adopted throughout the process. The actual development skill demand of enterprises is taken as the starting point of teaching and the building block development process is displayed by graphical data simulation to establish a mechanism that can evaluate the teaching process in real time. The aim is to explore the three ability training objectives of graphic processing technology in building block design teaching: the application ability of graphic processing technology, the transformation of innovative ideas and the data consolidation of design process. Theoretical modules are taught in the form of large courses, modules are used to improve students' understanding of course content, MOOCs are used to expand teaching content, and university-enterprise projects are completed to train students' design thinking and ability.

Taking the course of building blocks teaching as an example, which is offered in the fourth semester of professional teaching, students have completed the study of relevant design theories and possess certain innovation and execution ability, which can meet the implementation mode of parallel application of graphics processing technology and teaching. In the early stage of the course, a set of $3 \mathrm{D}$ software data of building blocks and toys is developed with the assistance of enterprises for the implementation and application of the course teaching, which is also the necessary condition for the teaching reform of graphic processing technology of building blocks and toys design. Combined with students' ability and quality in the teaching stage of the building blocks course, based on the application of graphics processing technology and without limiting the application of graphics software in the course teaching, it is the basic condition for the application of graphics processing technology in the teaching of building block toy design for students to complete the learning of software (3DMAX/ Maya /C4D) in the professional basic course. In the course, students no longer display the course assignments in the original hand-drawn form, but use the graphic software to simulate the final form of the display design and show the results of the assignments in the most intuitive way. $t$ the same time, students also have a certain ability of design and innovation, and play a leading role in the design and application of course graphics processing technology to ensure the accuracy and rationality of course teaching. In the application of information-based teaching, the classroom is no longer confined to a specific teaching site. The application of mobile SCVE, WeChat Live, Ding Talk and other interactive APP software improves the interaction of teaching and plays a key role in the personalized cultivation of students.

The application reform of graphics processing technology makes the course teaching more close to the requirements for talent of enterprises and allows valuation of the theoretical design in teaching. Visualized graphic data management actually enhances students' interest in the course, and enables students to understand all aspects of building block design and development from theory to design implementation. The course establishes a complete database of building blocks graphic cases, teaching models, building blocks Mosaic animation, etc., so that students can use teaching materials for learning at any time. At the same time, establishing students' personal documents through the Internet vocational education platform allows more intuitive and accurate judgment of the content of the course teaching problems, and monitoring of the actual progress of students' classroom learning in real time. It can reduce students' information load on teaching content, enhance students' interaction and initiative in course teaching, eliminate the blind side in knowledge in original building block design theory teaching, and establish a set of simulation 
system that can evaluate each link of course teaching process. Visualized graphics processing technology can remove the original bricks and toys teaching trivial matters, optimize the creative, discussion, design, implementation and other course tasks and ensure the accuracy and rationality of the course teaching

\subsection{School-enterprise Project Docking Relying on the Information-based Teaching Curriculum}

As a pilot major of the college's "engineering business" integration Project-based talent training mode, project system courses add "business" link based on its original emphasis on the combination of theory and practice, which emphasizes the delivery of teaching results, and promotes the optimization and continuous improvement of teaching results through the competitive test of market circulation link. The city where the school is located is the core area of the toy industry, and it has the best industrial resources. School-enterprise interaction can promote the real implementation of teaching and scientific and technological achievements. The application of graphics processing technology also reduces the demand for the site of the university-enterprise project docking, and can simulate the development issues such as project technology and structure with graphics data, reduce the capital investment and time cost of enterprises, and improve the commercialization landing ability of the university-enterprise project cooperation.

During the implementation of the schoolenterprise project of information-based teaching, students have mastered the application of graphic processing technology in building block design, and the visualized building block graphics have basically enabled the evaluation of the shape, color, process and structure required by enterprise development. The practicality of course teaching can be deepened through school-enterprise cooperation projects. At this stage, the focus is on cultivating students' executive ability and team assistance ability, and designs and evaluates creative concepts through graphic technology in multiple levels of modeling, structure and function. A school-enterprise project cooperation teaching mode with "theoretical decomposition — graphic execution - network evaluation and feedback platform output" is constructed. Relying on the Internet vocational education platform, the course can build the graphic sample of course work, and carry out online project docking with enterprises. Enterprises can directly modify and optimize the design graphic data of course building blocks, and then decompose the design of model feedback class, so as to strengthen students' required abilities for actual project development. In the process of project operation, WeChat live, Ding Talk, conference, QQ remote control and other software were used for real-time feedback, and the final school-enterprise cooperation sample was demonstrated by the market, enterprises and sales parties in the form of graphic simulation, which ensured the accuracy and rationality of product development. The data collection and arrangement of the work content of project, and uploading it to the SCVE and other teaching platforms, can accumulate more and more complete actual execution data cases for the course, and optimize the teaching resources of building block design course.

As a major course of toy design, "Building Block Design" has been opened in 2017. Through the application of information-based teaching, the annual number of building block design positions for graduates has increased from $5 \%$ to $20 \%$, and a school-enterprise project cooperative teaching mode featuring "theoretical decomposition graphic execution - network evaluation and feedback - platform output" has been established. Having seen horizontal project development agreements signed with many enterprises, this course completed the development of particle building blocks series such as Mecha Cyclone, Earth Strikes Back, Monopoly, Counter-Strike, etc., creating social value of more than 50 million yuan for enterprises.

\subsection{Construction of Teachers and Resources for Information-based Teaching Application}

First of all, the information-based teaching brings about the change of teaching philosophy. The curriculum is no longer based on the traditional teaching mode of one lesson and one teacher. The teaching team of information-based teaching is formed by the mixed-teaching team of schools and enterprises and the variable live online teaching. Variable online instruction is arranged by teaching or according to project phase work. When a particular module task is executed according to the school-enterprise project, the enterprise will assign professionals of the module to conduct standard online broadcast explanation, and the contents of 
multiple tasks will be completed by personnel of different enterprises. This has solved the information load of teachers and improved the flexibility of classroom teaching. The use of the cross-border teacher sharing of Chinese universities in MOOC expands the comprehensive teaching knowledge points of the course and prepares students for their career growth in the future. As information-based teaching application has constructed the school-enterprise teacher database unique to the course, the teacher team is no longer subject to the regional and time constraints. The diversified course teacher team provides professional personal ability training for the course teaching, and gets rid of the teaching problem that students are all alike.

The information-based teaching resources of building block design course are promoted on the intelligent vocational education platform with standardized courses, with a total of 102 materials of $12 \mathrm{G}$ and 860 minutes of video length. Among them, there are 23 teaching courseware, 20 enterprise development cases, 63 teaching videos and 126 operation models. The Baidu Netdisk project storage space is built, so that real-time teaching status can be uploaded to the cloud in the form of data, offline classroom can be extended online, and the form of professional teaching resource library can be opened to realize the personalized customization of course teaching services. The real-time resource sharing is realized through SCVE, Ding Talk and Baidu Netdisk in internal teaching, and a WeChat official account for the toy design major is built as the external exchange platform, so as to achieve the industry drainage of teaching achievements. The official account includes modules such as coursework, innovation information, project achievement display, graduation and employment, etc., to establish a better and faster teaching evaluation mechanism, and also to broaden the course information teaching channels. Integrating the professional teaching factory data resources and classifying different material manufacturers into the course teaching resources allows students to find corresponding suppliers online according to their own design needs, quickly complete the task of "creative-design-model making", and construct teaching resources in line with the development of professional characteristics.

\section{CONCLUSION}

Through the teaching application of information technology, the course creates a more intuitive teaching classroom of building blocks design for students, expands the width of the teaching mode, establishes the Internet data repository of different platforms around the course and outside, and the effective integration of innovative ideas and design implementation in the classroom improves students' comprehensive practical ability. The graphic processing technology runs through the whole course teaching in the form of digital simulation to ensure the accuracy and rationality of the course teaching, and realize the win-win situation between the information-based teaching of toy design and the development of school-enterprise projects.

\section{AUTHORS' CONTRIBUTIONS}

This paper is independently completed by Sisu Chen.

\section{REFERENCES}

[1] Zuo Jingwu. Innovative Design of Children's Puzzling Toy [J]. Scientific and Technological Innovation, 2021, (02): 187-188. (in Chinese)

[2] Deng Wei, Bin Songren, Ci Lijun. Application of Parametric Design of Toy Product Modeling [J]. Design, 2021, 34(01): 11-13. (in Chinese)

[3] Quanheng Li. Analysis on the Sustainability of Home Supplies Design [M]. ICASSEE 2017, ISBN (on-line): 978-94-6252-438-5, 2017, 11: 277-279.

[4] Liu Shuai, Nie Yadong, Ren Wenying. Research on Emotion Evaluation of Children's Educational Toys Based on Fuzzy Analytic Hierarchy Process [J]. Industrial Design, 2020, (12): 2. (in Chinese)

[5] Sun Jianzheng, Li Ziye. Application Analysis of Digital Media Technology in Internet Environment [J]. Heilongjiang Science, 2019 (02): 112-113. (in Chinese)

[6] Deng Weibin, Liu Pan, Zhang Ke. Research on Modular Design of Toys [J]. Popular Art, 2019 (02): 106-107. (in Chinese)

[7] Wu Lifeng. Research on the Construction and Implementation Path of Collaborative Innovation Platform for Art Design Talent 
Cultivation Based on Studio [J]. Design. 2018,

(24): 106-108. (in Chinese) 